\title{
900V SiC Based, Hybrid, Multilevel DC/DC Topology for 1500VDC PV Application
}

\author{
Branislav Stevanović, Diego Serrano, Miroslav Vasić, Pedro Alou, Jesús Angel Oliver and José Antonio Cobos \\ Universidad Politécnica de Madrid (UPM) \\ Centro de Electrónica Industrial (CEI) \\ José Gutiérrez Abascal, 2, 28006 Madrid (Spain) \\ Tel. +34910676 930, Fax. +34915645966 \\ Email: \{branislav.stevanovic, diego.serrano, miroslav.vasic, pedro.alou, jesusangel.oliver, ja.cobos\}@upm.es
}

\begin{abstract}
Very compact, highly efficient, hybrid DC/DC topology, consisted of a standard interleaved boost converter followed by a multilevel Resonant Switched Capacitor Converter (RSCC), that employs 900V Silicon-Carbide (SiC) devices, for use in emerging, two-stage, grid connected 1500V Photo-Voltaic (PV) systems is presented in this paper. Operation principle of this topology is described: controllability of its output voltage and power processing distribution among its stages in function of input voltage. Depending on operating region, certain amount of input power is not processed, but it is transfered directly to the output. This behaviour increases significantly efficiency of the analyzed topology, compared to the solutions presented in literature. The presented topology obtains full ZVS transitions in all operating conditions, even without load. ZVS transitions and employed $\mathrm{SiC}$ MOSFETs are the key elements for the high converter efficiency. Triangular Conduction Mode (TCM) in boost stage and resonant switching technique in RSCC part are used to obtain ZVS transitions in all the switches under wide range of loads and PV voltages. Results of multivariable optimization (pareto front) for the presented topology are provided. Previousely described theoretical analysis is fully experimentally confirmed by building and measuring a $10 \mathrm{~kW}$ prototype of $8.26 \mathrm{~kW} / \mathrm{kg}$ of specific power and $404.6 \mathrm{~cm}^{3}$ of volume occupied only by power stage components. Euro efficiency of $\mathbf{9 9 . 4 8} \%$ in nominal input/output voltage conditions is achieved.
\end{abstract}

\section{INTRODUCTION}

$\mathbf{T}$ wo-stage, grid connected PV system, presented in Fig. 1a, has improved energy harvesting capability, but bigger size, weight and cost, compared to its one-stage counter pair, presented in Fig. 1b. After several changes in the standard voltage level of PV strings $(600 \mathrm{~V}, 1000 \mathrm{~V})$, most of important PV industry players are adopting 1500 VDC with the objective of achieving a cost decrease associated with the smaller currents in different installation points which is reflected in the amount of employed copper. General comparison between 1000VDC and 1500VDC PV systems and main advantages and drawbacks of the increment of DC bus voltage level are presented in [1].

Additionally, the behaviour of real PV strings under real enviromental conditions in sample location, for which data are available in [2], is processed by the authors in order to numerically justify the change from 1000VDC to 1500VDC and use of DC/DC stage in grid connected PV system. Behaviour of MPP voltage during one year period for 1000VDC and 1500VDC PV strings and different AC grid connections are presented in Fig. 2. Estimated values of the (Energy harvested)/(Financial profit) per one year for these systems

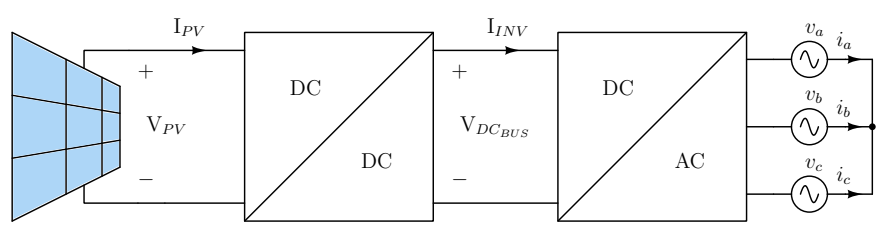

(a)

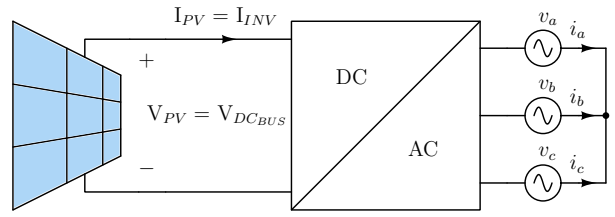

(b)

Fig. 1: Grid connected PV system: a) Two-stage. b) One-stage.

TABLE I: Estimation of (Energy harvesting)/(Financial profit) per year in a sample location for different combinations of (PV string)/(AC grid) connections (Fig. 2). It was assumed energy price of $120 \$$ /MWh.

\begin{tabular}{c|cc|cc}
\hline \hline $\begin{array}{c}\text { PV string } \\
\text { connection } \\
\text { AC grid } \\
\text { connection }\end{array}$ & 1000VDC & $1500 \mathrm{VDC}$ & $1500 \mathrm{VDC}$ & $1500 \mathrm{VDC}$ \\
DC/DC stage & Included & Not included & Not included & Included \\
\hline $\begin{array}{c}\text { Energy havested } \\
\text { per year }\end{array}$ & $49.22 \mathrm{MWh}$ & $53.05 \mathrm{MWh}$ & $52.11 \mathrm{MWh}$ & $53.05 \mathrm{MWh}$ \\
$\begin{array}{c}\text { Financial profit } \\
\text { per year }\end{array}$ & $5906.4 \$$ & $6366.5 \$$ & $6253.2 \$$ & $6366.5 \$$ \\
\hline \hline
\end{tabular}

are listed in Tab. I. Several conclusions can be extracted from the presented results: 1) Change of PV open circuit voltage from $1000 \mathrm{VDC}$ to $1500 \mathrm{VDC}$ will produce improvement of harvested energy by $4 \mathrm{MWh}$ per year with $20 \mathrm{~kW}$ system, 2) $\mathrm{DC} / \mathrm{DC}$ stage is not necessary in $1500 \mathrm{VDC} \mathrm{PV}$ system with 400VAC grid connection, 3) Inclusion of DC/DC stage in 1500VDC PV system with 600VAC grid connection gives minor financial benefit compared to the increased size and cost and 4) Inclusion of a DC/DC stage in 1500VDC PV system is mandatory for grid connections of 800VAC and higher.

PV array voltage range extension with two-stage grid connection scenario is presented in [3]-[4]. For the DC/DC stage it is proposed a solution based on a mini-boost, that represents standard boost topology that would operate only in regions of low MPPT voltages (otherwise would be bypassed by a parallel diode or an active switch) according to the introduced concept of power envelope and, thus it is rated for lower power levels. However, semiconductor and passive 


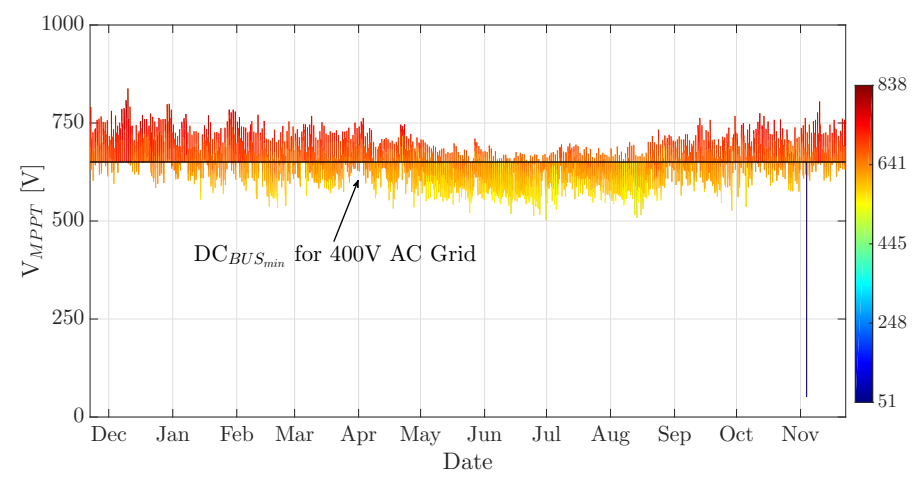

(a)

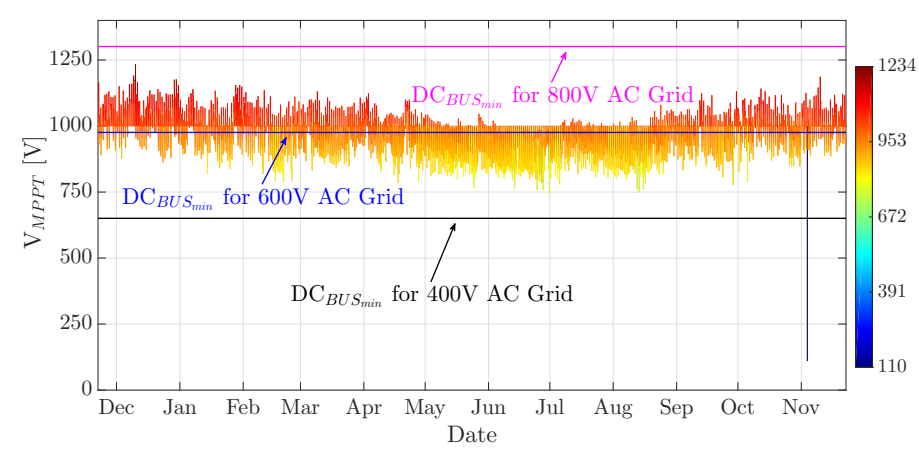

(b)

Fig. 2: Variation of MPP voltage of PV string during one year period (19. 12. 2016. - 19. 12. 2017.) in a sample location. MPP curves are estimated for "Canadian Solar CS6X-305P" PV module. Solar irradiance measurements are taken for tilt angle $\beta=40^{\circ}$ south by "LI-200" instrument. Measurements of ambient temperature are taken from "CR800 MTwr Temp" instrument. Minimal values of DC bus voltages for different $\mathrm{AC}$ grid connections are calculated under assumption of $3 \mathrm{H}-\mathrm{ZS}$ modulation technique in the inverter stage and included $\pm 15 \%$ variation of grid voltage level. a) $1000 \mathrm{~V}$ PV string $\left(\mathrm{N}_{\mathrm{ser}}=19, \mathrm{~N}_{\mathrm{par}}=5\right)$. b) $1500 \mathrm{~V}$ PV string $\left(\mathrm{N}_{\mathrm{ser}}=28, \mathrm{~N}_{\mathrm{par}}=4\right)$.

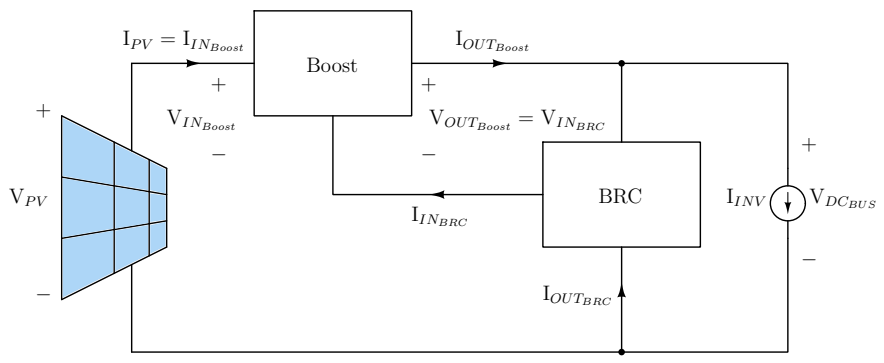

Fig. 3: Block diagram of the proposed DC/DC topology.

components in this two-level solution are rated for full DC bus voltage which influences maximal efficiency arround $98 \%$ in $25 \mathrm{~kW}$ prototype. In [5] a three-level topology for DC/DC stage is proposed. It reduces voltage stress on the devices to the half of DC bus voltage. Unfortunately, maximal efficiency less than $99 \%$ for the DC/DC part in $3 \mathrm{~kW}$ prototype can be considered as low.

The wide voltage variation of the PV panel (500V-1500V) worsens drastically the performance of the DC/AC converter. Thus, use of a DC/DC stage allows to provide a narrow voltage variation, which will lead to a better DC/AC characteristics. The optimum DC bus voltage is a trade-off between the performance of the DC/DC converter and the DC/AC converter. On the other hand, medium power inverter for decentralized

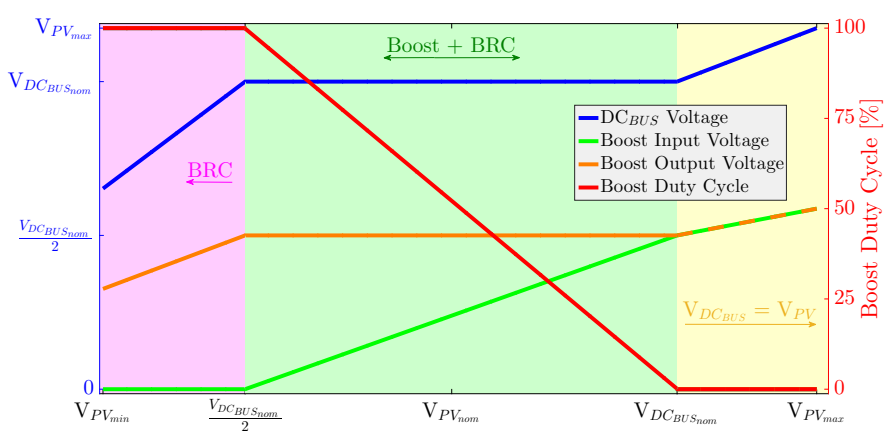

(a)

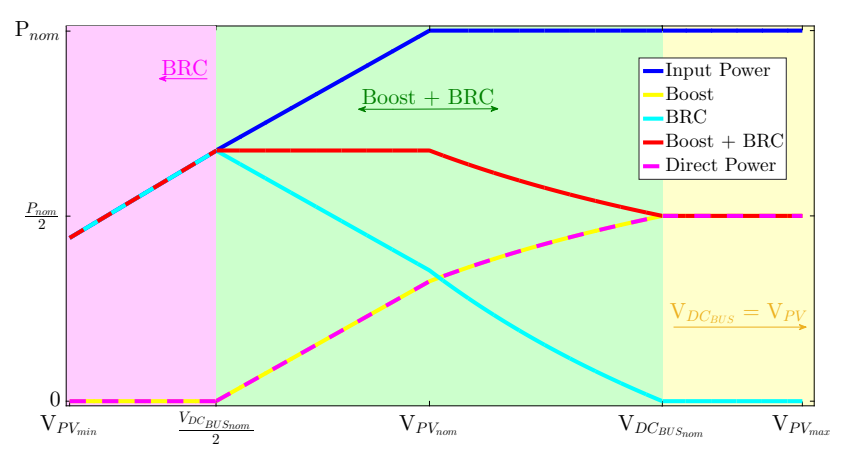

(b)

Fig. 4: Operating regions of the proposed DC/DC topology as a function of PV voltage: a) Voltage controllability. b) Power flow distribution among the stages.

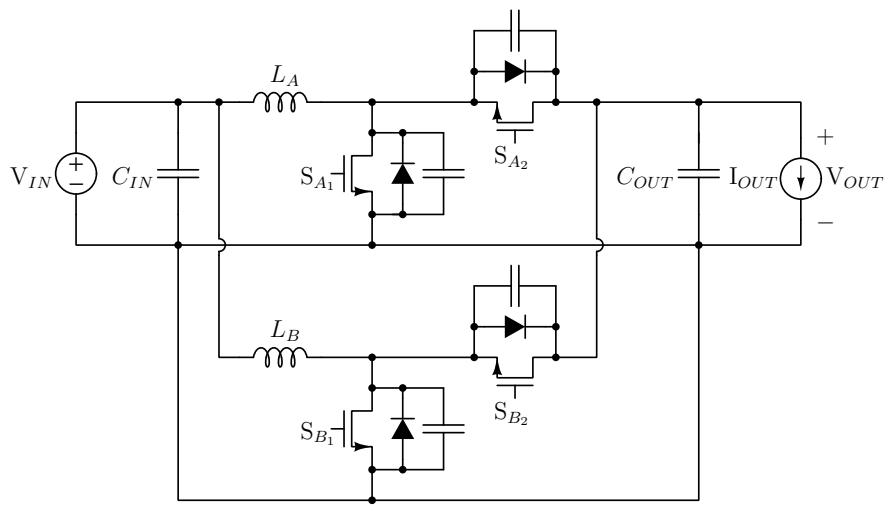

Fig. 5: Boost stage schematic.

PV plants shall be designed with the weight for maximum of two people lifting for installation (e.g., $<70 \mathrm{~kg}$ ) [1]. In order to compromise these two problems, high-power density and controllability of DC bus voltage, hybrid topology that combines highly efficient, non-controllable step-up Resonant Switched Capacitor Converter (RSCC) and controllable, but lower efficient boost topology is proposed in this paper.

\section{Proposed DC/DC StAGE}

Block diagram of the proposed DC/DC topology is presented in Fig. 3. Similar concept is shown in [6] (LFT Loss Free Transformer) for use in a three-phase rectifier for controlled electric drives. It is consisted of standard boost stage that operates in closed loop and controls its output voltage and Basic Resonant Cell (BRC) stage that operates in open loop with $50 \%$ of duty cycle at resonant frequency and has constant, non-changable boosting factor of 2 , but processes power in a very efficient way. 


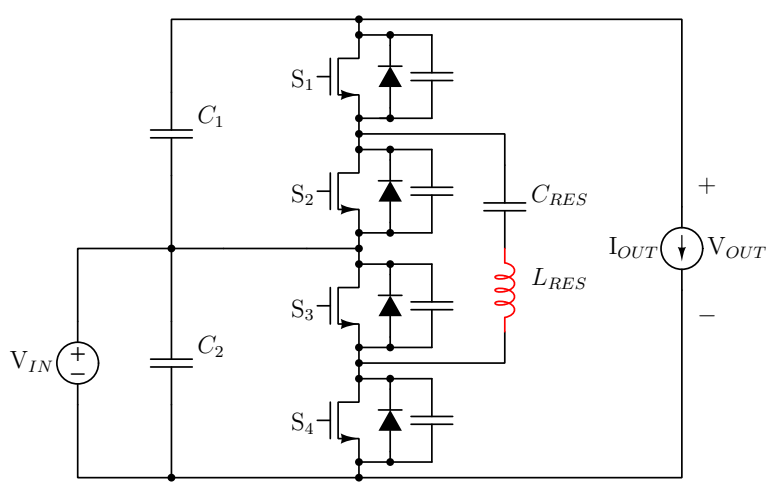

(a)

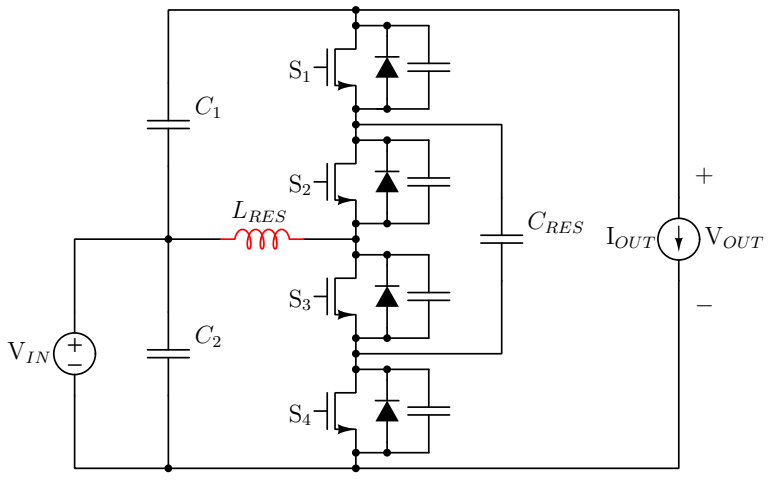

(c)

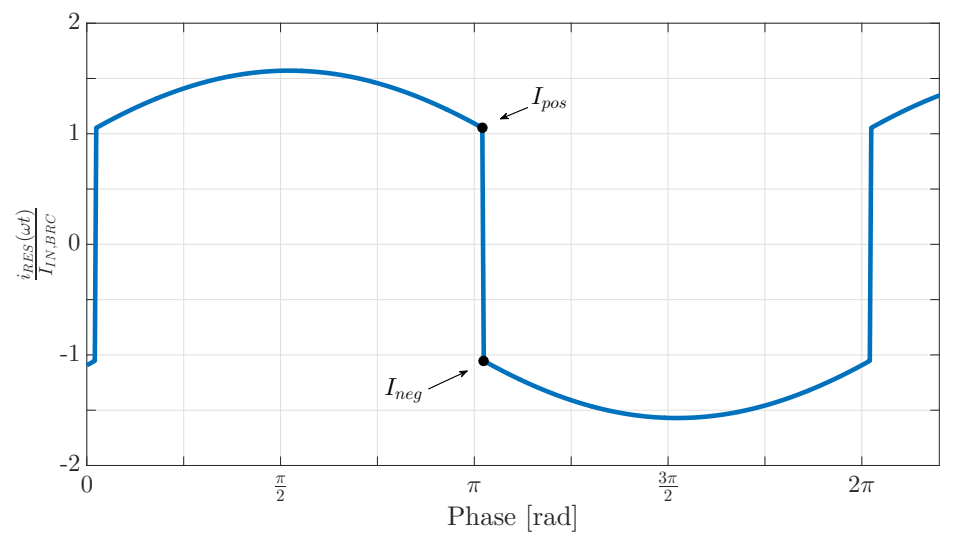

(b)

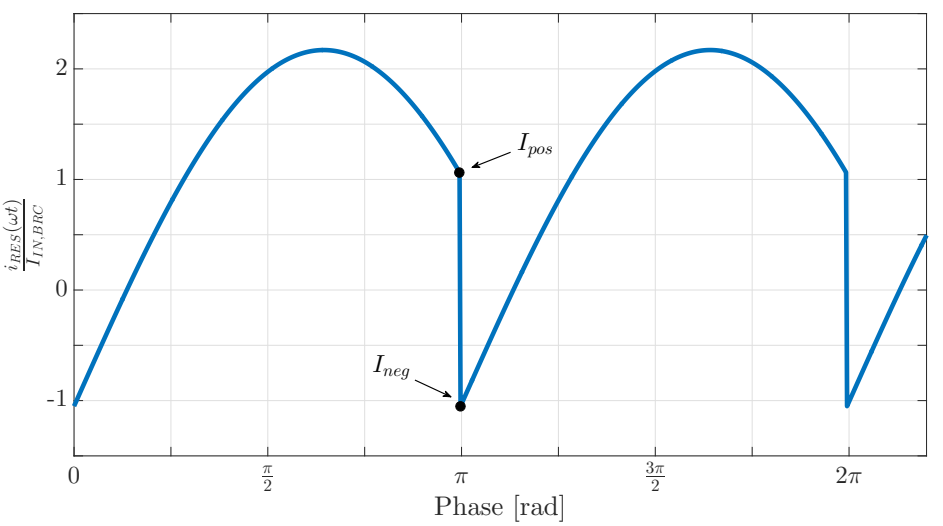

(d)

Fig. 6: BRC stage: a) AC side inductor - schematic. b) AC side inductor - inductor current waveform. c) DC side inductor - schematic. d) DC side inductor - inductor current waveform.

In Fig. 4a three operating regions of the presented topology can be noticed. In the middle region both stages are operative and output voltage is controlled. Boundaries of this region are determined by saturation of boost duty cycle to its maximal and minimal values. Bellow $V_{\mathrm{DC}}$, BUSnom $/ 2$ low-side switch of boost converter is shorted and total input voltage is transfered to the low-side DC bus capacitor of the BRC stage $\left(C_{2}\right.$ capacitor in Fig. 8a). In this region boosting factor is 2 , which is the maximum value for this topology. For $V_{\mathrm{PV}}$ voltages higher than $V_{\mathrm{DC}}$, BUSnom , input and output are shorted by closing high-side switch of the boost stage. In this region BRC converter still operates in order to keep proper voltage distribution among DC bus capacitors. Finally, boosting factor of the proposed topology can be described as:

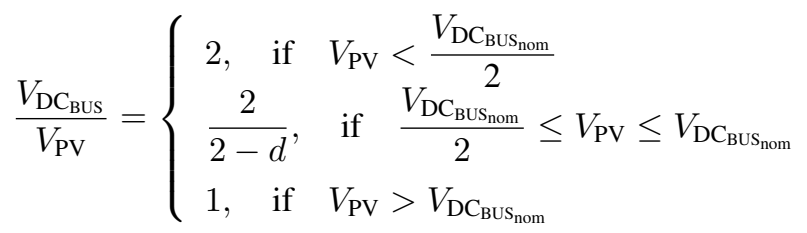

where $d$ is duty cycle of boost stage (part of switching period where its low side switch is closed).

Placement of the output of boost converter to the highside DC bus capacitor of BRC stage $\left(C_{1}\right.$ capacitor in Fig. 8a) provides additional, direct path of power flow from input to the output, beside power processing through boost and BRC part. This means that total power is not processed by the converter, which increases the efficiency of the presented topology. Power distribution among the stages of this topology is presented in Fig. 4b. Only in the region $V_{\mathrm{PV}}<V_{\mathrm{DC}}$, BUSnom $/ 2$ total input power is processed by the converter. However, this processing is done in a very efficient way by the BRC part, while in the boost stage only DC conduction losses of low-side switch and inductor winding are present. In the rest of operating region, processed power is always less than the total input power. The power processed by BRC stage has its maximum at boundary point between first and middle region $\left(V_{\mathrm{PV}}=V_{\mathrm{DC}}\right.$, BUSnom $\left./ 2\right)$ and reaches zero in region $V_{\mathrm{PV}}>V_{\mathrm{DC}}$, BUSnom. Amount of power processed by boost stage and power directly transfered to the output match in all operating regions and spread from zero value for $V_{\mathrm{PV}}<V_{\mathrm{DC}}$, BUSnom $/ 2$ up to $P_{\mathrm{nom}} / 2$ for $V_{\mathrm{PV}}>$ $V_{\text {DC, BUSnom }}$.

\section{A. Design Aspects and Optimization Results}

Arrangment of the boost and BRC stage reduces voltage rating of semiconductor components to the half of DC bus voltage. Due to the fact that boost stage processes total input current of the converter (Fig. 3), interleaving technique is introduced in order to reduce input current ripple and $\mathrm{AC}$ current stress in the input filter capacitor. It was decided to go with 2 phases operating in parallel, as a compromise between ripple cancelation, complexity and cost of the system. Additionally, with increment in number of phases, sensitivity of the concept on tolerances of circuit components increases [7] - [8]. In order to achieve ZVS transitions under wide range of PV voltages and load levels, it is decided for boost stage to operate in TCM with variable switching frequency. Simplified 


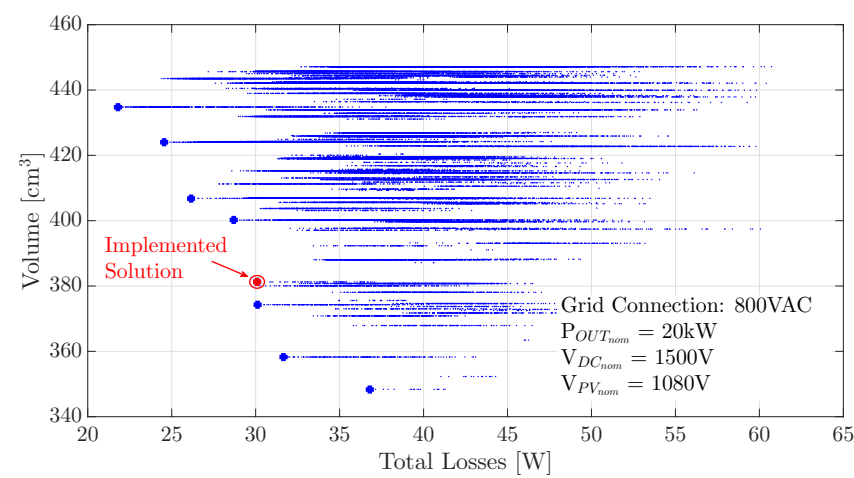

(a)

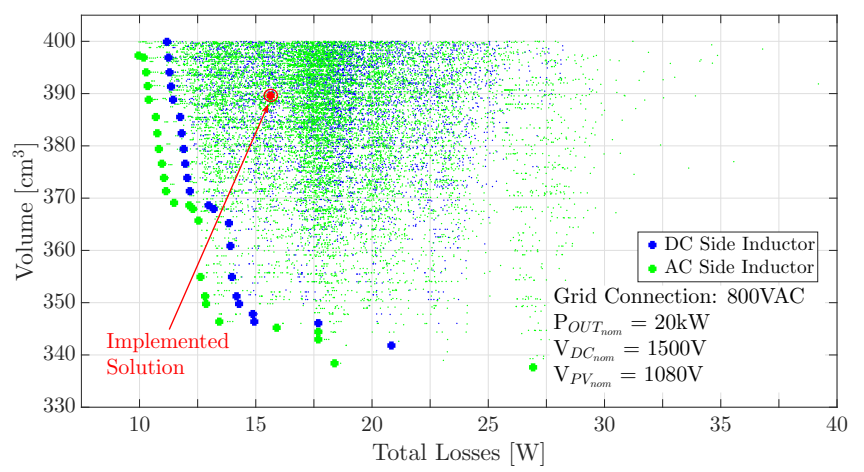

(b)

Fig. 7: Optimization results at nominal operating point (Tab. II). Presented results assume that total output power of $20 \mathrm{~kW}$ is processed by two $10 \mathrm{~kW}$ converters placed in parallel. In the optimization process it was allowed up to $3 \mathrm{SiC}$ devices in parallel for each switch. a) Boost stage. b) BRC stage.

TABLE II: Specifications and design of the power stage of the prototype.

\begin{tabular}{|c|c|c|c|c|}
\hline \multicolumn{2}{|c|}{ Nominal conditions } & Boost & BRC & Total \\
\hline \multicolumn{2}{|c|}{$P_{\text {nom }}$} & $3.05 \mathrm{~kW}$ & $3.89 \mathrm{~kW}$ & $10 \mathrm{~kW}$ \\
\hline \multicolumn{2}{|c|}{$V_{\mathrm{IN}, \text { nom }}$} & $330 \mathrm{~V}$ & $750 \mathrm{~V}$ & $1080 \mathrm{~V}$ \\
\hline \multicolumn{2}{|c|}{$V_{\text {OUT, nom }}$} & $750 \mathrm{~V}$ & $1500 \mathrm{~V}$ & $1500 \mathrm{~V}$ \\
\hline \multicolumn{2}{|c|}{ Sw. Freq. } & $64 \mathrm{kHz}$ & $13.2 \mathrm{kHz}$ & \\
\hline \multirow{3}{*}{ MOSFET } & Device & C3M0120090J & C3M0120090J & \\
\hline & N. in Par. & 3 & 3 & $y$ \\
\hline & Volume & $4 \times 3 \times 427 \mathrm{~mm}^{3}$ & $4 \times 3 \times 427 \mathrm{~mm}^{3}$ & $8 \times 3 \times 427 \mathrm{~mm}^{3}$ \\
\hline \multirow{2}{*}{$\begin{array}{c}\text { MOSFET } \\
\text { Driver }\end{array}$} & Component & CRD-001 & CRD-001 & I \\
\hline & Volume & $4 \times 24.65 \mathrm{~cm}^{3}$ & $4 \times 24.65 \mathrm{~cm}^{3}$ & $8 \times 24.65 \mathrm{~cm}^{3}$ \\
\hline \multirow{3}{*}{$C_{I N}$} & Value & $14 \mu \mathrm{F}, 900 \mathrm{~V}$ & & \\
\hline & Component & C4AEOBW5140A3JJ & / & I \\
\hline & Volume & $43.51 \mathrm{~cm}^{3}$ & & $43.51 \mathrm{~cm}^{3}$ \\
\hline \multirow[b]{2}{*}{$C_{D C, B U S}$} & Value & $2 \times 12$ & $900 \mathrm{~V}+2 \times 0.75 \mu \mathrm{F}, 900 \mathrm{~V}$ & \\
\hline & Component & 2XC4AEOB & $120 \mathrm{~A} 3 \mathrm{FJ}+6 \times \mathrm{B} 580311925$ & M062 \\
\hline \multirow{3}{*}{$C_{R E S}$} & Value & & $4.5 \mu \mathrm{F}, 900 \mathrm{~V}$ & \\
\hline & Component & I & 3XC4AEOBU4150A1WJ & I \\
\hline & Volume & & $3 \times 6.93 \mathrm{~cm}^{3}$ & $3 \times 6.93 \mathrm{~cm}^{3}$ \\
\hline \multirow{8}{*}{$L$} & Value & $210 \mu \mathrm{H}$ & $74 \mu \mathrm{H}$ & \\
\hline & Core & $\mathrm{PQ} 32 / 30$ & 55071 & \\
\hline & Material & 3C97 & MPP60u & \\
\hline & Gap & $2.2 \mathrm{~mm}$ & I & I \\
\hline & Wire & Litz $200 \times 0.071 \mathrm{~mm}$ & Litz $100 \times 0.2 \mathrm{~mm}$ & \\
\hline & N. of Turns & 48 & 34 & \\
\hline & $R_{D C}$ & $78 \mathrm{~m} \Omega$ & $83 \mathrm{~m} \Omega$ & \\
\hline & Volume & $2 \times 26.7 \mathrm{~cm}^{3}$ & $10.23 \mathrm{~cm}^{3}$ & $63.63 \mathrm{~cm}^{3}$ \\
\hline \multicolumn{2}{|c|}{ Weight } & $530 \mathrm{~g}$ & $580 \mathrm{~g}$ & $1.21 \mathrm{~kg}$ \\
\hline \multirow{2}{*}{\multicolumn{2}{|c|}{$\begin{array}{c}\text { Specific Power } \\
\text { Total Components Volume }\end{array}$}} & $5.75 \mathrm{~kW} / \mathrm{kg}$ & $6.71 \mathrm{~kW} / \mathrm{kg}$ & $8.26 \mathrm{~kW} / \mathrm{kg}$ \\
\hline & & $200.6 \mathrm{~cm}^{3}$ & $204 \mathrm{~cm}^{3}$ & $404.6 \mathrm{~cm}^{3}$ \\
\hline
\end{tabular}

schematic of two-phase interlaved boost stage is displayed in Fig. 5.

Schematics of the BRC stage are displayed in Fig. 6a and $6 \mathrm{c}$, while their correspoinding inductor current waveforms are presented in Fig. $6 \mathrm{~b}$ and $6 \mathrm{~d}$. As it can be noticed, resonant inductor can be placed either in series with resonant capacitor ("AC side inductor", Fig. 6a), either in series with

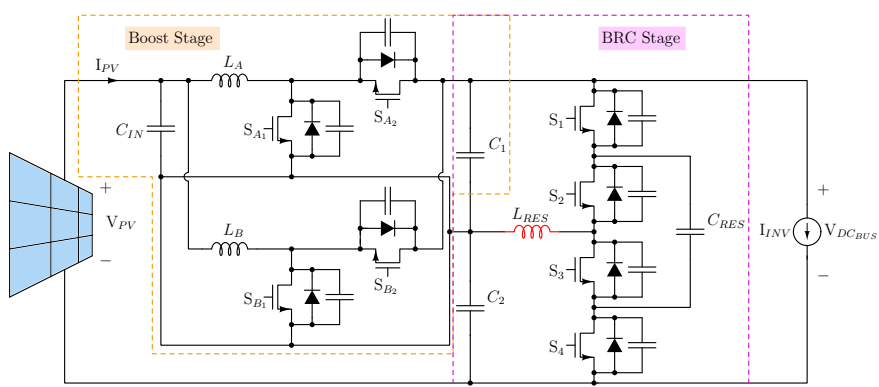

(a)

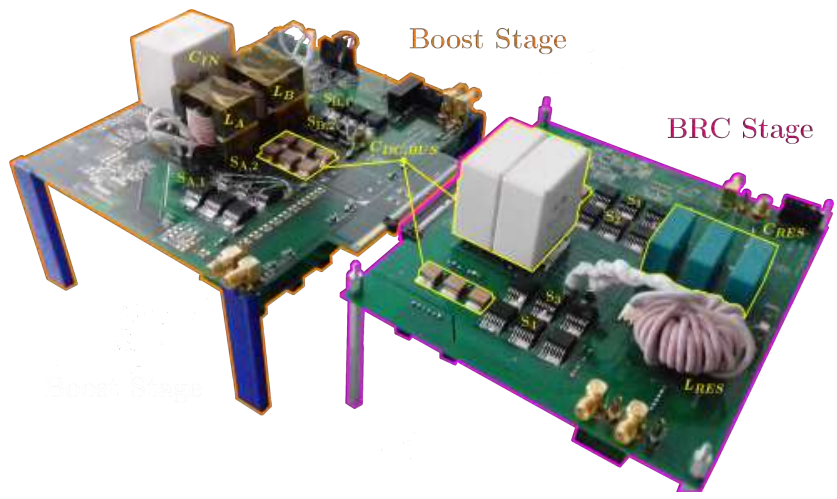

(b)

Fig. 8: a) Schematic of the power stage of the proposed DC/DC topology. b) Photo of the prototype. Labels in the photo correspond to the labels in the schematic.

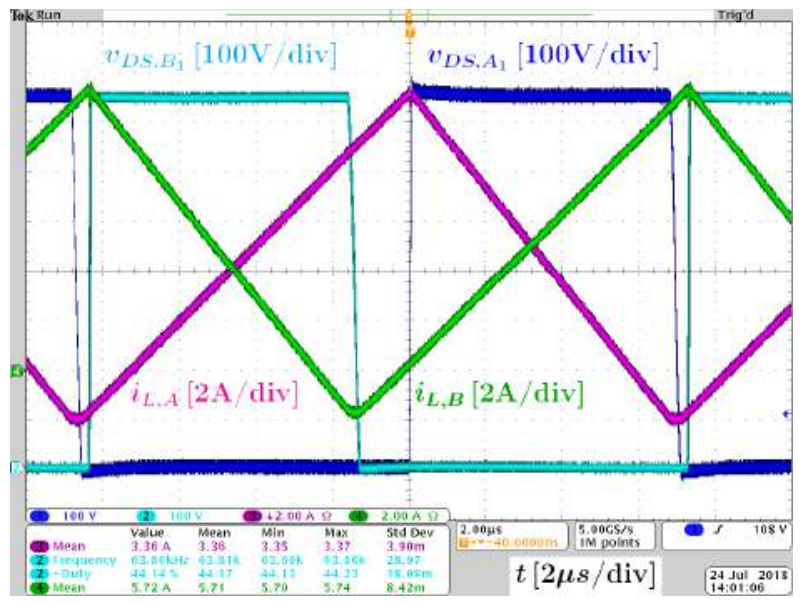

Fig. 9: Boost stage waveforms (Ch. 1 - drain-source voltage of $\mathrm{S}_{\mathrm{A}, 1}$, Ch. 2 - drain-source voltage of $\mathrm{S}_{\mathrm{B}, 1}$, Ch. 3 - phase A inductor current, Ch. 4 - phase B inductor current) at nominal point.

input connection ('DC side inductor", Fig. 6c). Details related to these variations, ZVS transitions, corresponding switching sequences and wide load operation issue are described in details in [9] and [10]. As it is shown in Fig. 6b and 6d, inductor current waveform deviate from sine and rectified sine wave, which means that switching frequency is slightly higher than resonant frequency even under nominal load conditions. This is due to the fact that switching transitions from $S_{1}-S_{3}$ to $\mathrm{S}_{2}-\mathrm{S}_{4}$ and vice versa need to be started with certain amount of energy in resonant inductor in order to achieve ZVS [11]. Main equations of current waveforms for $\mathrm{AC}$ side inductor case are presented in [12]. In general, position of the resonant inductor do not influence normal operation of the circuit - switches are 


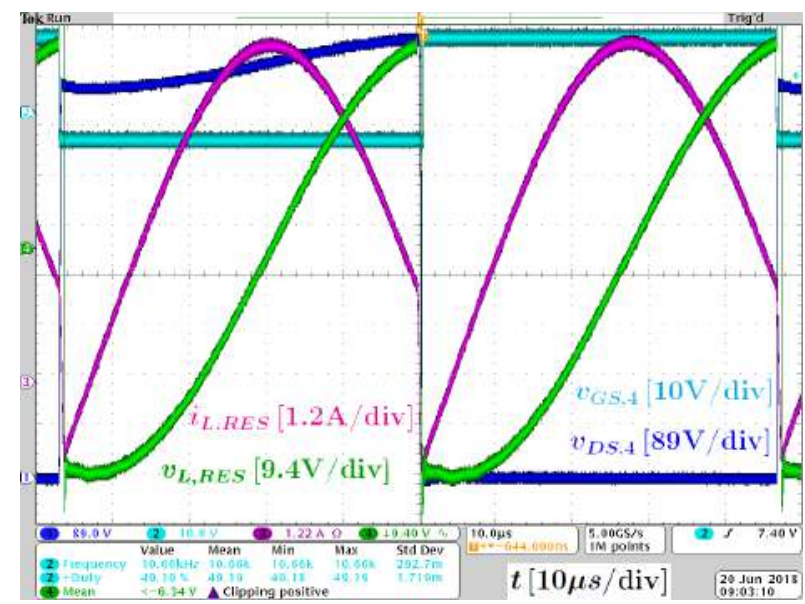

(a)

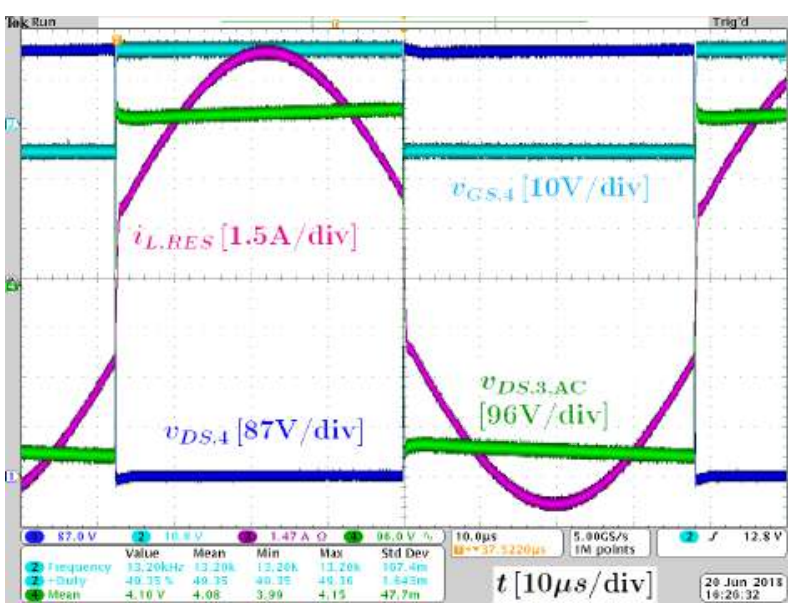

(c)

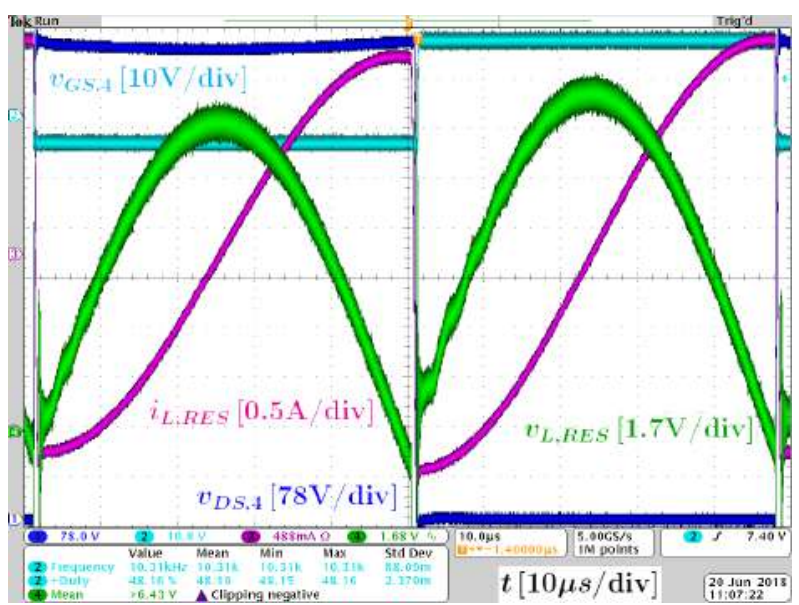

(b)

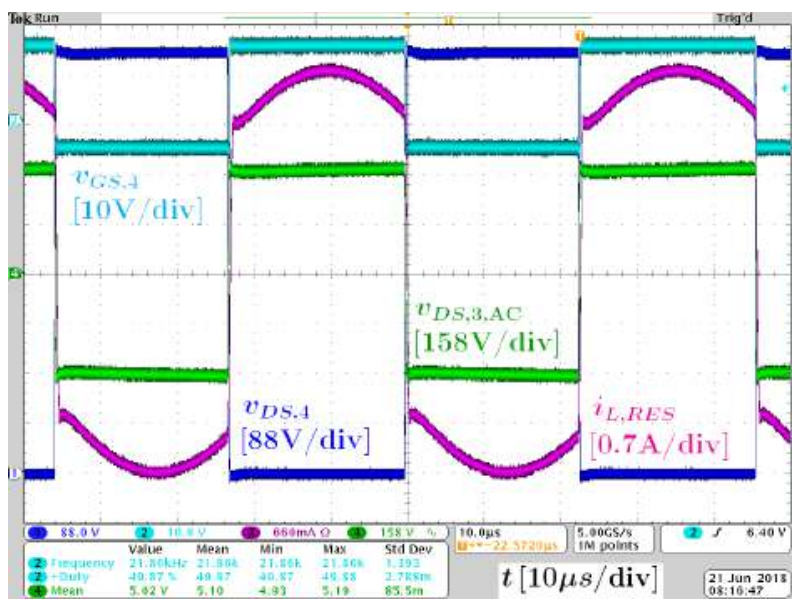

(d)

Fig. 10: BRC stage waveforms (Ch. 1 - drain-source voltage of $\mathrm{S}_{4}$, Ch. 2 - gate-source voltage of $\mathrm{S}_{4}$, Ch. 3 - resonant inductor current, Ch. 4 - (resonant inductor voltage)/(drain-source voltage of $\mathrm{S}_{3}$ (AC coupling))): a) DC side resonant inductor - nominal power. b) DC side resonant inductor - no load. c) AC side resonant inductor - nominal power. d) AC side resonant inductor - $\mathbf{4 5} \%$ of nominal power.

alternatively switched in pairs, $\mathrm{S}_{1}-\mathrm{S}_{3}$ and $\mathrm{S}_{2}-\mathrm{S}_{4}$, and obtained boosting factor is 2 . However, this change impacts a lot design of the inductor and operation under low load conditions. While in the case of DC side inductor ZVS transition is achievable even under no load condition, decrement of load even down to $50 \%$ for $\mathrm{AC}$ side inductor can double switching frequency compared to the nominal operating point. This behaviour is experimentally confirmed.

Optimization process is done for both stages. The optimization includes: $4 \mathrm{SiC} 900 \mathrm{~V}$ devices from Wolfspeed/Cree, 89 magnetic corres from Ferroxcube (29 of EE, 4 of EFD, 25 of ETD, 19 of POT, 6 of PQ and 6 of RM), 4 magnetic materials from Ferroxcube (3C90, 3C91, 3C95, 3C96), 31 wire diameters (AWG10-41) and 900V film capacitors from KEMET for both stages. Additionally for BRC optimization are also included: 33 MPP powder cores and MPP60u material from Magnetics. Film capacitor technology is selected for $C_{R E S}$ and bulky capacitors according to the analysis presented in [13]. Results of optimization (pareto front [14]) are shown in Fig. $7 \mathrm{a}$ and $7 \mathrm{~b}$. It can be noticed that $\mathrm{AC}$ side inductor case in BRC stage provides more efficient and smaller solutions. However, AC side inductor solution has problem in operation under low load, which cancels this advantage in nominal conditions.

\section{EXPERIMENTAL RESULTS}

Experimental verification of the presented concept is obtained by building a $10 \mathrm{~kW}$ prototype which specifications and power stage design are listed in Tab. II. Total schematic and photo of the prototype is given in Fig. 8. Fig. 9 shows the waveforms of the boost converter in nominal operating point. Operation of BRC part in nominal point is displayed in Fig. $10 \mathrm{a}$ and $10 \mathrm{c}$.

Fig. 10b and 10d present waveforms of BRC with DC side inductor under no load and BRC stage with AC side inductor under $45 \%$ of nominal load, respectively. It is confirmed that ZVS condition with DC side inductor is achievable even under no load conditions, while in the case of AC side inductor switching frequency is almost doubled (from $13.2 \mathrm{kHz}$ up to $21.86 \mathrm{kHz}$ ) at $45 \%$ of nominal load. In order to face this problem, different modulation techniques could be applied under low load conditions with AC side inductor - burst mode [9]. Due to these results it was decided BRC variation with DC side inductor to be included in final converter design.

Results of efficiency measurements in nominal input/output voltage case under differenet levels of load is displayed in 


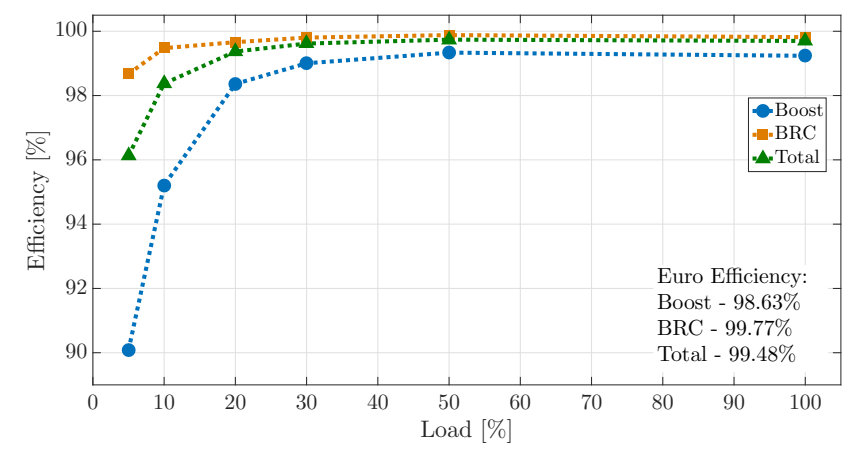

(a)

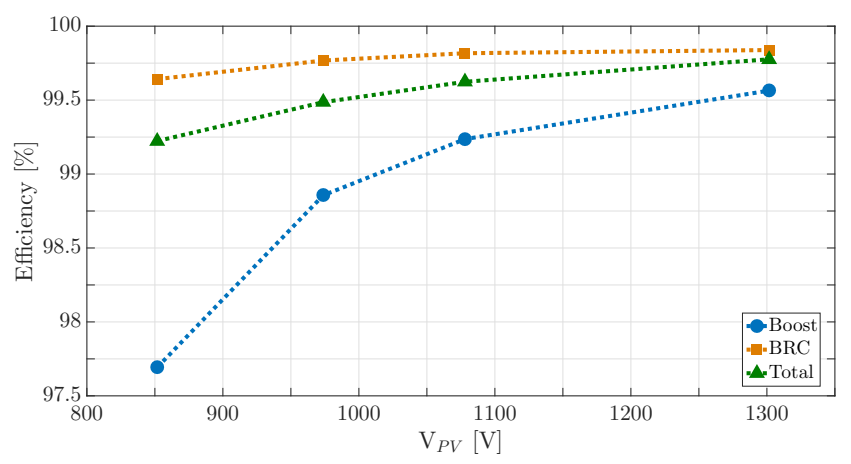

(b)

Fig. 11: a) Measured efficiency in nominal input/output voltage (Tab. II) under different loads. b) Measured efficiency for nominal power curve (Tab. II, Fig. 4b) in different points of PV voltage.

Fig. 11a and in the case of nominal power curve (Tab. II, Fig. 4b) for different PV voltages in Fig. 11b. It can be seen that euro efficiency of $99.48 \%$ in nominal input/output voltage conditions with specific power of $8.26 \mathrm{~kW} / \mathrm{kg}$ and $404.6 \mathrm{~cm}^{3}$ occupied volume only by power stage components is achieved.

\section{CONCLUSION}

In order to compromise two contradictory demands, highpower density and controllability of DC bus voltage, hybrid DC/DC topology that combines highly efficient, noncontrollable step-up Resonant Switched Capacitor Converter (RSCC) and controllable, but lower efficient boost topology, for use in emerging, two-stage, grid connected 1500VDC Photo-Voltaic (PV) is proposed in this paper. In the presented solution all employed devices have to withstand half of the output voltage, therefore, $900 \mathrm{~V} \mathrm{SiC} \mathrm{MOSFETs} \mathrm{present} \mathrm{an}$ excellent option, having in mind that $\mathrm{Si}$ MOSFET do not reach these votlages and due to $\mathrm{SiC}$ MOSFET superiority over Si IGBTs. The benefits of the proposed topology are that it has full ZVS transitions in the complete operating range from the point of view of the load demand and input voltage and that it is a hybrid topology in which the total power is not processed partially through the resonant converter or through the boost converter. The total power is processed only in the case of extremely low input voltage, when it is necessary to provide a constant gain of two, but even in this case, it is performed in a very efficient way through the presented resonant converter. In order to have full ZVS transitions, Triangular Conduction Mode (TCM) with variable frequency in boost stage is performed. Results of multivariable optimization (pareto front) for the presented topology are provided. Two possible variations of BRC stage are analyzed and included in optimization. It is concluded that AC side inductor case provides more efficient and smaller solutions under nominal conditions. However, this variation has problem in operation under low load, which cancels this advantage.

Previousely described theoretical analysis is fully experimentally confirmed by building and measuring a $10 \mathrm{~kW}$ prototype of $8.26 \mathrm{~kW} / \mathrm{kg}$ of specific power and $404.6 \mathrm{~cm}^{3}$ of volume occupied only by power stage components. Euro efficiency of $99.48 \%$ in nominal input/output voltage conditions is achieved.

\section{ACKNOWLEDGMENT}

The work presented in this paper has been partially supported by the research project DPI2017-88505-C2-1-R (Soluciones optimas para el procesado de la energia de las nuevas plantas solares de $1500 \mathrm{~V}$ con conexion a la red elctrica) funded by the Spanish government (Ministerio de Ciencia, Innovacion y Universidades).

Branislav Stevanović holds a predoctoral contract under RD99/2011, with a grant from the 'Programa Propio' by the 'Universidad Politécnica de Madrid'.

The authors would like to thank to colleague Uroš Borović for help and usefull advices during the design of PCBs.

\section{REFERENCES}

[1] E. Serban, M. Ordonez, and C. Pondiche, "DC-Bus Voltage Range Extension in 1500V Photovoltaic Inverters," IEEE Journal of Emerging and Selected Topics in Power Electronics, vol. 3, Dec., pp. 901-917, 2015.

[2] AOCS. National Renewable Energy Laboratory (NREL), Solar Radiation Research Laboratory (SRRL), [Online]. Available: www.nrel.gov. [Accessed: Dec. 2017].

[3] E. Serban, F. Paz, and M. Ordonez, "PV array voltage range extension for photovoltaic inverters using a mini-boost," 2016 IEEE Energy Conversion Congress and Exposition (ECCE), 2016, pp. 1-8.

[4] E. Serban, F. Paz, and M. Ordonez, "Improved PV Inverter Operating Range Using a Miniboost," IEEE Transactions on Power Electronics, vol. 32, pp. 8470-8485, 2017.

[5] J. S. Kim, J. M. Kwon and B. H. Kwon, "High-Efficiency Two-Stage Three-Level Grid-Connected Photovoltaic Inverter,' IEEE Transactions on Industrial Electronics, vol. 65, pp. 2368-2377, 2018.

[6] P. J. Grbović, P. Delarue and P. Le Moigne, "A Novel Three-Phase Diode Boost Rectifier Using Hybrid Half-DC-Bus-Voltage Rated Boost Converter,' IEEE Transactions on Industrial Electronics, vol. 58, pp. 1316-1329, 2011.

[7] O. Garcia, P. Zumel, A. de Castro, and J. A. Cobos, "Effect of the Tolerances in Multi-Phase DC-DC Converters," 2005 IEEE 36th Power Electronics Specialists Conference, 2005, pp. 1452-1457.

[8] S. Waffler, J. Biela, and J. W. Kolar, "Output ripple reduction of an automotive multi-phase bi-directional dc-dc converter," 2009 IEEE Energy Conversion Congress and Exposition, 2009, pp. 2184-2190.

[9] M. Vasić, D. Serrano, P. Alou, J. A. Oliver, P. Grbović, and J. A. Cobos, "Comparative analysis of two compact and highly efficient resonant switched capacitor converters," Applied Power Electronics Conference and Exposition (APEC), 2018, pp. 2168-2174.

[10] D. Serrano, V. Toral, M. Vasić, J. A. Oliver, P. Alou, and J. A. Cobos, "Advantages of Gallium Nitride over Silicon transistors in soft-switched Resonant Switched Capacitor Converters," CIPS 2018 - 10th International Conference on Integrated Power Electronics Systems, 2018.

[11] M. Kasper, R. M. Burkart, G. Deboy, and J. W. Kolar, "ZVS of Power MOSFETs Revisited,' IEEE Transactions on Power Electronics, vol. 31, pp. 8063-8067, 2016.

[12] K. Sano, T. Arai, H. Fujita, "Reducing output current ripple of resonant switched-capacitor step-up converter with interleaving technique," The 2010 International Power Electronics Conference - ECCE ASIA, 2010, pp. 1635-1641. 
[13] M. Vasić, J. A. Oliver, P. Alou, J. A. Cobos and P. Grbović, "Experimental Evaluation of Capacitors for High Power Resonant Converters," PCIM Europe 2017; International Exhibition and Conference for Power Electronics, Inteligent Motion, Renewable Energy and Energy Management, 2017, pp. 1-6.

[14] J. W. Kolar, J. Biela, and J. Miniböck, "Exploring the pareto front of multi-objective single-phase PFC rectifier design optimization - $99.2 \%$ efficiency vs. $7 \mathrm{~kW} / \mathrm{dm}^{3}$ power density," 2009 IEEE 6th International Power Electronics and Motion Control Conference, 2009, pp. 1-21. 